\title{
Analysis of Thermal Conduction in the Machine Border Collapse: Numerical and Experimental Comparison
}

\author{
Giancarlo Ferreira Matos, Diego Alves de Miranda \\ Department of Mechanical Engineering, University of the Region of Joinville-UNIVILLE, Joinville, Brazil \\ Email: giancarlo.ferreira9@gmail.com
}

How to cite this paper: Matos, G.F. and de Miranda, D.A. (2019) Analysis of Thermal Conduction in the Machine Border Collapse: Numerical and Experimental Comparison. Open Access Library Journal, 6: e5178. https://doi.org/10.4236/oalib.1105178

Received: January 11, 2019

Accepted: January 22, 2019

Published: January 25, 2019

Copyright $\odot 2019$ by author(s) and Open Access Library Inc.

This work is licensed under the Creative Commons Attribution International License (CC BY 4.0).

http://creativecommons.org/licenses/by/4.0/ (c) (i) Open Access

\begin{abstract}
The success of a design of a machine manufacturing line is directly related to the efficiency in the use of raw material and components, requiring a total control of the process. In this work the numerical simulation was applied to analyze the conduction of heat transferred in the Edge gluing machine Smc1 and to validate the simulations with the temperature differences collected experimentally. These validations were performed with the collection of temperatures via thermal imaging, which provides greater accuracy of thermal conduction capture. The results obtained are similar in relation to certain points captured by thermal imaging. The thermal model analyzed represents proximity to the heat distribution during the use of the machine.
\end{abstract}

\section{Subject Areas}

Computer Engineering, Experimental Physics, Mathematical Analysis

\section{Keywords}

3D Heat Transfer, Numerical Simulation, Finite Volumes Method

\section{Introduction}

In recent years, progress has been made in relation to numerical simulation and process monitoring techniques, with the aim of improving and verifying efficiency through the creation of virtual models. Due to the great search in the area of research and development of computational analysis, the simulation of processes is highlighted. Oba [1] applied numerical simulation to compare experimentally with furnaces used in the production of ceramic blocks, in which the simulation was applied to solve the thermal problem of a complete tunnel and to 
analyze the influence of several parameters in the operation of the equipment. Other dissertations helped to understand the theme, as an example of Oliveira [2], referring to the thermal modeling of the reciprocal linear compressor operating without lubricating oil, being its model developed to adopt a prediction of the velocity and temperature fields, as well as heat in different regions of the compressor.

Barban [3] analyzed the tensions generated in materials, after the welding, generating a model of the temperature distribution during the process and Teixeira [4] where he carried out the analysis of the thermal effect and the creep in the structures executed in layers, mainly in dams of concrete compacted with roll contributed in the understanding to the subject. Eger [5] performed the modeling of turbulent flows under the alternating rotation action that took advantage of fluid movement to reduce non-uniformity in composition, temperature and other properties. Barrios [6] performed a thermal modeling, aiming to know the heat flux generated during the milling process, thus being able to determine better cutting conditions and also to design new products with better performance. Pereira [7] performed the thermal analysis of a small 3D printing, promoting a new model of region studied, reducing its heating by $50 \%$, aiming to solve problems of instability.

In this context, it is intended to apply a three-dimensional heat conduction simulation, observing the transfer of heat from the surface of the contact area of the heaters in relation to the structural assembly of the edge-sealing machine, so that fluid can be viscoplastic in the appropriate temperature range.

\section{Methods}

This paper aims to analyze the thermal performance of conductive heat transfer in the machine system through the structure, components and product (viscoplastic), collecting data, performing numerical simulation and experimentally comparing the results in order to validate the use of the heaters they provide heat to the system maintaining the indicated temperature range of application of the viscoplastic fluid, without compromising its flow. Thus reducing costs in components and preparation as the use of thermal paste and machining of the positions of the heaters.

\subsection{Study Equipment}

The structural assembly shown in Figure 1 comprises the storage of the viscoplastic ethylene vinyl acetate fluid and flows through a spindle to its point of application in accordance with the indicated temperature range of $130^{\circ} \mathrm{C}$ to $160^{\circ} \mathrm{C}$.

Figure 1(a) depicts the assembly of reservoir parts, axle holder, scraper, applicator shaft and glue and Figure 1(b) shows the exploded view of the assembly. In order to carry out the heat transfer, the set uses four cartridge heaters of $400 \mathrm{~W}$ each, totaling $1600 \mathrm{~W}$. Their positions are represented in Figure 2.

For their assembly shown in Figure 1 it is necessary to apply thermal paste in 
order to fix the heaters in their proper positions. Its positions of 3 heaters are applied horizontally in the reservoir and one is applied vertically between the reservoir assembly and the axis support.

\subsection{Equipment Capabilities and Processing Parameters}

The set analyzed in this work is part of the SmC1 SmartmaqCollapse machine, represented in Figure 3, which according to the company's website is a Collapse designed for beginner and medium-sized carpenters, with optional extensor tables that can also be used for larger jobs.

The SmC1 Collapse shown in Figure 3 has the largest opening of the glue box on the market; this facilitates cleaning the collet without removing the glue box and has the ability to glue edge ribbons from materials such as PVC, ABS, paper and wood, with glue width up to $80 \mathrm{~mm}$ [8]. Its technical specifications are:

1) Tape thickness: 0.3 to $2.0 \mathrm{~mm}$;) Maximum tape width: 10 to $80 \mathrm{~mm} ; 3$ ) Table dimensions: $870 \times 600 \mathrm{~mm}$; 4) Auxiliary tables (optional); 5) Feed rate: 5.5 $\mathrm{m} / \mathrm{min}$; 6) Temperature $120^{\circ} \mathrm{C}$ to $220^{\circ} \mathrm{C}$; 7) Power: 1600 Watts; 8) Voltage: 220 V/110V-Single phase.

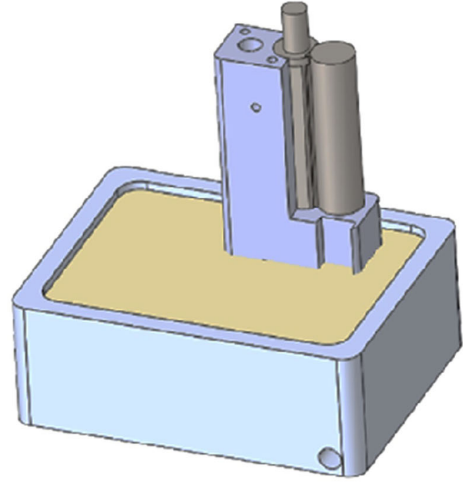

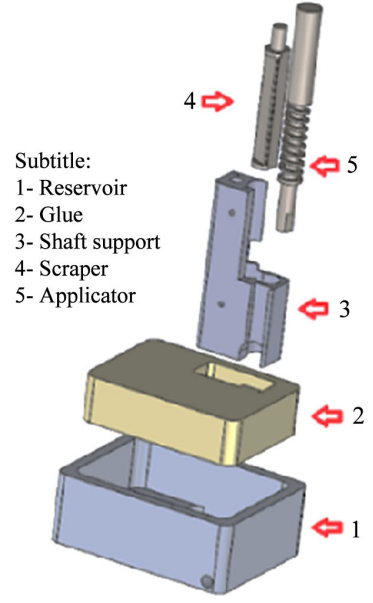

(b)

Figure 1. Structural set. (a) Isometric view. (b) Exploded view.

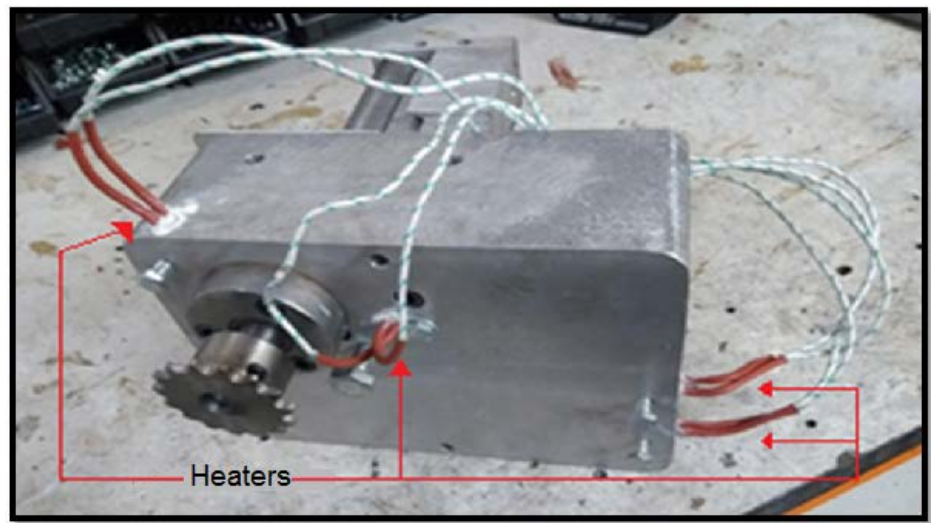

Figure 2. Heaters positions. 


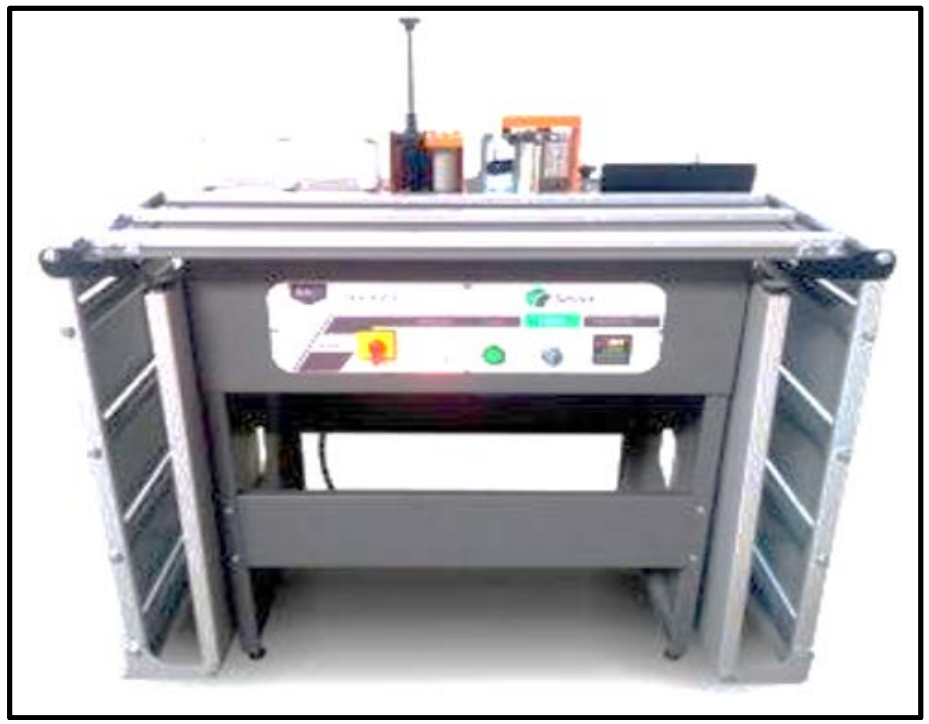

Figure 3. SmC1 SmartmaqCollar [8].

\subsection{Data Collect}

For a better understanding of the thermal performance performed in the structural set it is necessary to collect data as the time taken to heat the heaters as shown in Figure 4.

As shown in Figure 4(a) in about 1 minute the resistance reaches the temperature of $247.9^{\circ} \mathrm{C}$ and Figure 4 (b) off after 10 minutes it still remains at elevated temperatures of $166.8^{\circ} \mathrm{C}$.

\subsection{Numerical Simulations}

Due to the complexity of the geometry analyzed as the example of the spindle in the applicator axis, it is necessary to transfer the CAD geometry to the ANSYS software. In order to perform the numerical simulation using the finite volume method, the mesh is shown in Figure 5.

The generation of the mesh for the proposed problem is of multi-block form to carry out its refinement as illustrated in Figure 5, being an important variant in the accomplishment of the thermal modeling.

\subsection{Contour Conditions}

The correct heat conduction in relation to the viscoplastic fluid used in the process is fundamental for the operation of the machine, being transmitted from the heat generation of the heaters positioned in the reservoir to the applicator axis. For the numerical simulation, the temperatures were applied according to Figure 6.

The temperatures of $247.9^{\circ} \mathrm{C}$ applied to the reservoir at the locations indicated in Figure 6 were experimentally collected according to Figure 4 and were considered as constants for the numerical simulation to represent the temperature in the contact area of the heater with the reservoir. 


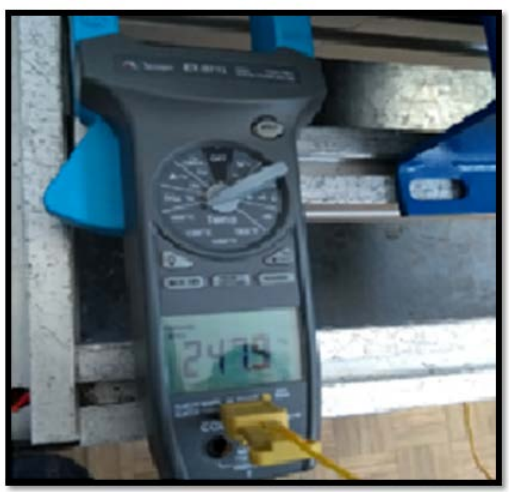

(a)

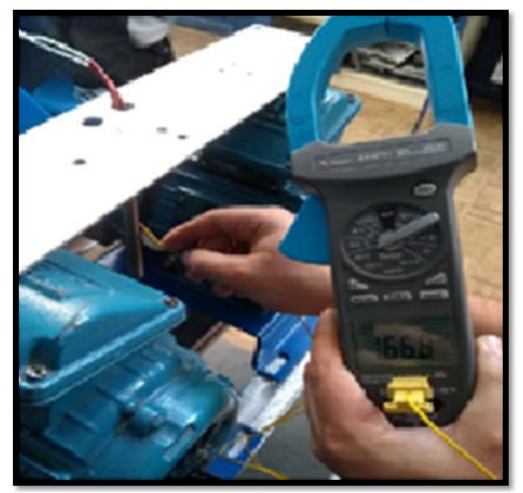

(b)

Figure 4. Heater temperature measurement. (a) Higher temperature. (b) After being switched off.

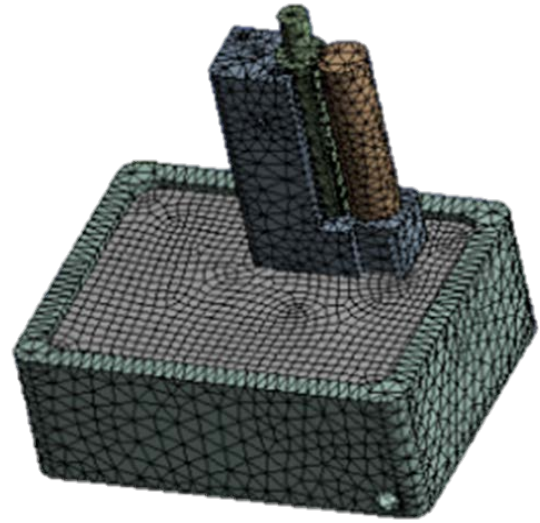

Figure 5. Generation of mesh.

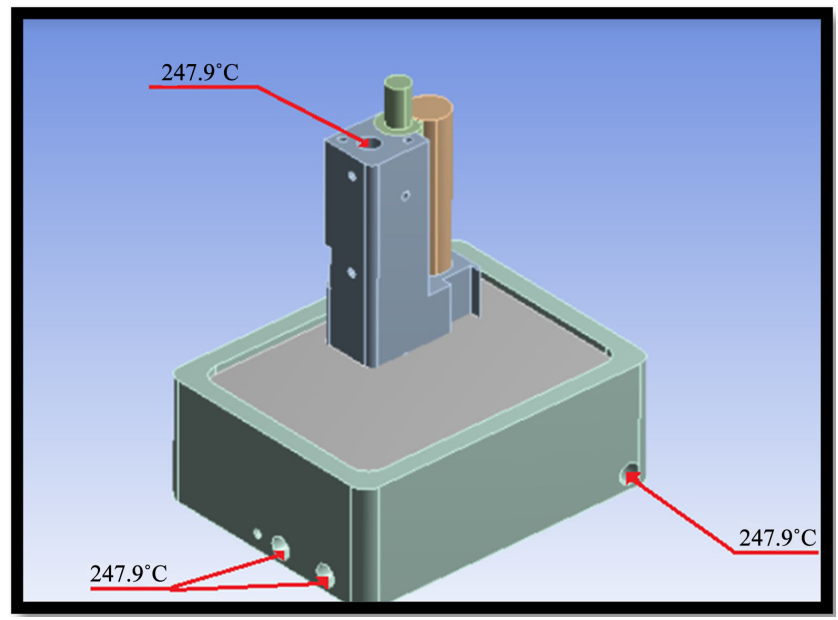

Figure 6. Application of temperatures.

\subsection{Validation}

In order to manage the heat distribution in the set, thermal photos of the mechanism were taken during its operation as shown in Figure 7.

The analysis with the help of the thermal imager model Fluke TI90 was per- 
formed to verify the thermal efficiency of the process at different points in the set and to validate the results obtained during the numerical simulation. Due to the need for the process, care was taken to ensure heat transfer to the applicator shaft. For this, a point thermometer was used for measurement according to Figure 8.

The temperature found in Figure 8 was $149.9^{\circ} \mathrm{C}$, remaining within what is suggested for the process.

\section{Results and Discussions}

The method used to understand the thermal model created was that of finite volumes, which has the principle of performing a subdivision of the structure analyzed in order to understand each element to understand the set. After the mesh generation procedure was applied to the experimentally collected temperature of the resistance in the contact faces of the mechanical assembly. For the elaboration of the numerical simulation, the initial temperature of $8^{\circ} \mathrm{C}$ was used for Figure 9(a) where the photo was taken during the winter period, requiring a longer time for heating and releasing the machine.

On the day in question the machine took approximately 6 minutes from $8^{\circ} \mathrm{C}$ to reach the temperature recorded in Figure 9 (b) of $131^{\circ} \mathrm{C}$. Collecting the thermal data can generate the thermal model presented in Figure 10, thus obtaining a better understanding of the physical phenomenon presented.

The virtual model shown in Figure 10 represents the transmission of the heat obtained numerically generated from the heaters in relation to the structural storage set of the machine after the period of 300 seconds, bringing the results closer to the actual situation. Thus the transient model created reached close thermal points in comparison to the thermal image captured during its operation, due to the considered temperature constant of the resistors. It is possible to compare the results according to Figure 11(a) representing the thermal modeling performed through simulations and Figure 11(b) thermal photo during the use of the mechanism.

As shown in Figure 11(a), the points found in simulation are similar to those found in practice in Figure 11(b) of their surface heat transfer, and therefore, the temperature distribution in a given section of the reservoir.

Figure 12 represents the transfer of heat in a section of the surface of the reservoir and exhibits in certain points temperatures near $250^{\circ} \mathrm{C}$ due to the proximity to the resistance in the place, but in average stays between $140^{\circ} \mathrm{C}$ within the parameters of work.

After the machine was started, the heaters take around 60 seconds to reach the temperature of $247.9^{\circ} \mathrm{C}$, which was considered as a constant for the simulation, thus performing the heat transfer to the mechanism. After 300 seconds reaches the average temperature of $150.9^{\circ} \mathrm{C}$ according to the numerical simulation performed as shown in Figure 13.

Figure 13 presents the maximum constant temperature, representing the re- 
sistances, the minimum temperature and its heating ramp during 300 seconds of simulation and average in relation to the two. According to data collected and numerical simulation, to sum up the heating times of the resistors and heat transfer, the device is released for its operation in approximately 6 minutes keeping steady state.

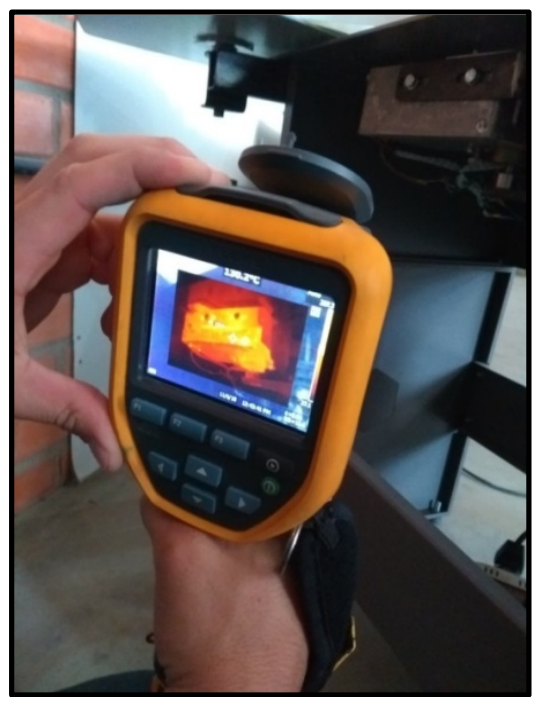

Figure 7. Thermal analysis.

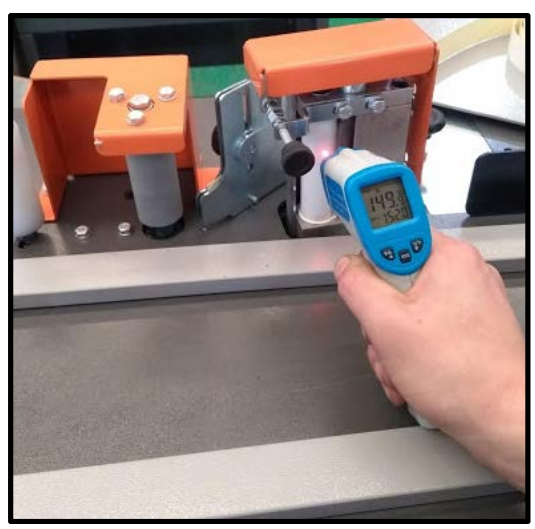

Figure 8. Thermal analysis.

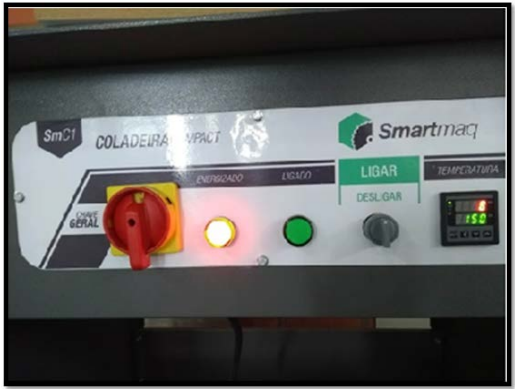

(a)

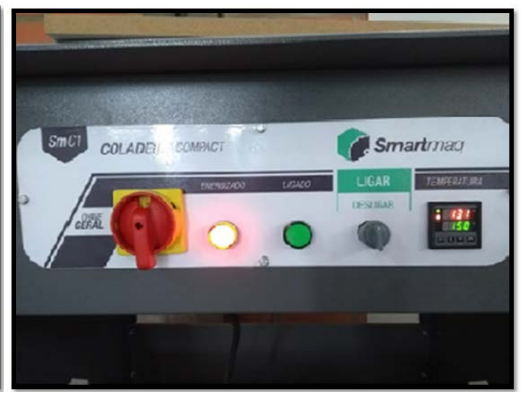

(b)

Figure 9. Temperature display. (a) Initial temperature. (b) Temperature after its activation. 


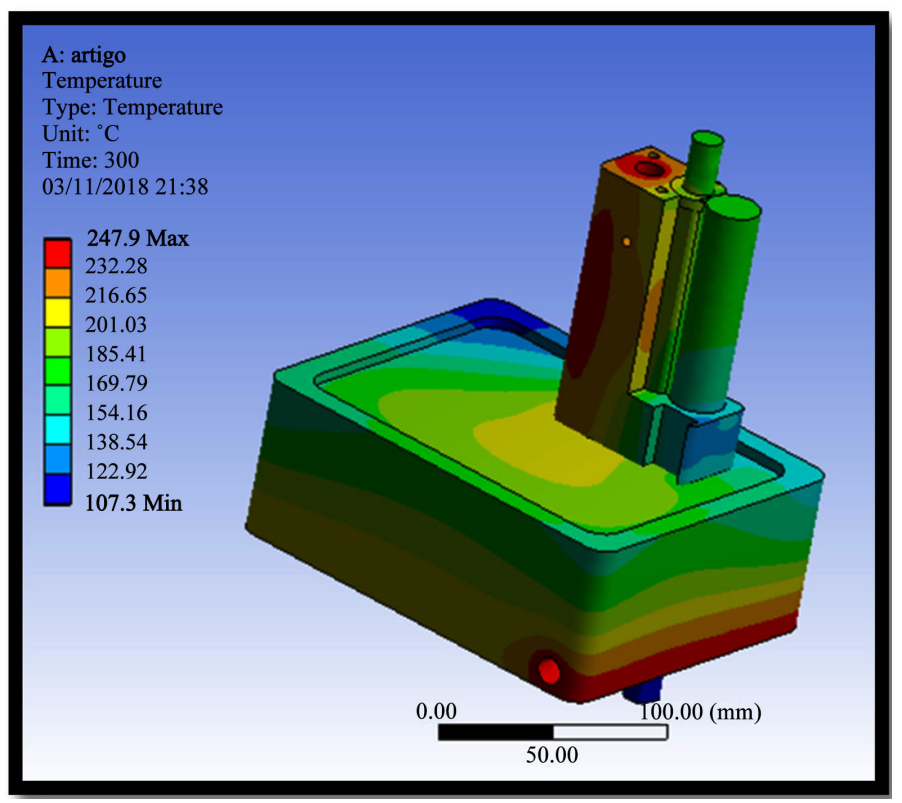

Figure 10. Analyzed set.

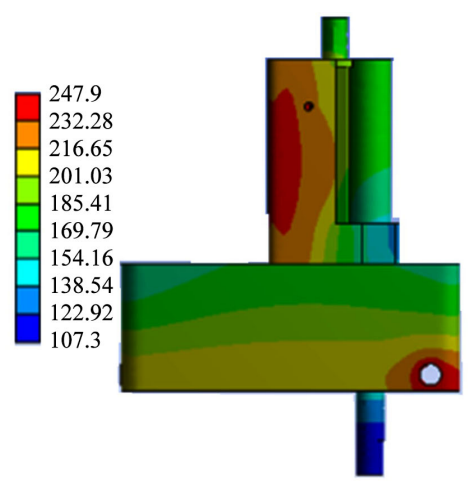

(a)

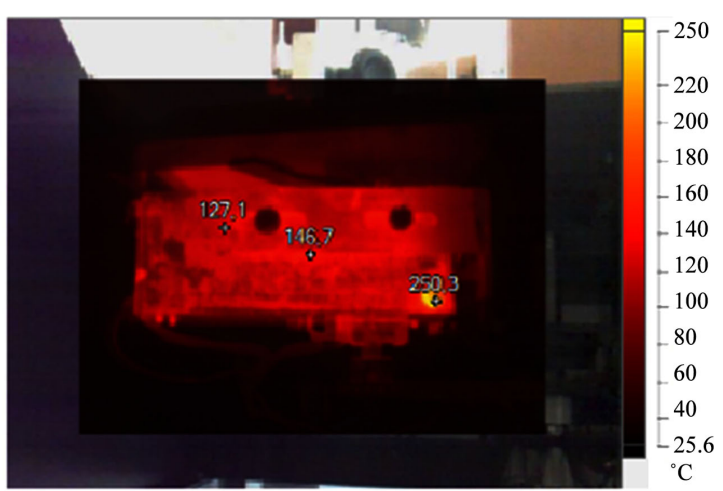

(b)

Figure 11. Comparison of results found. (a) Thermal modeling. (b) Thermal photo.

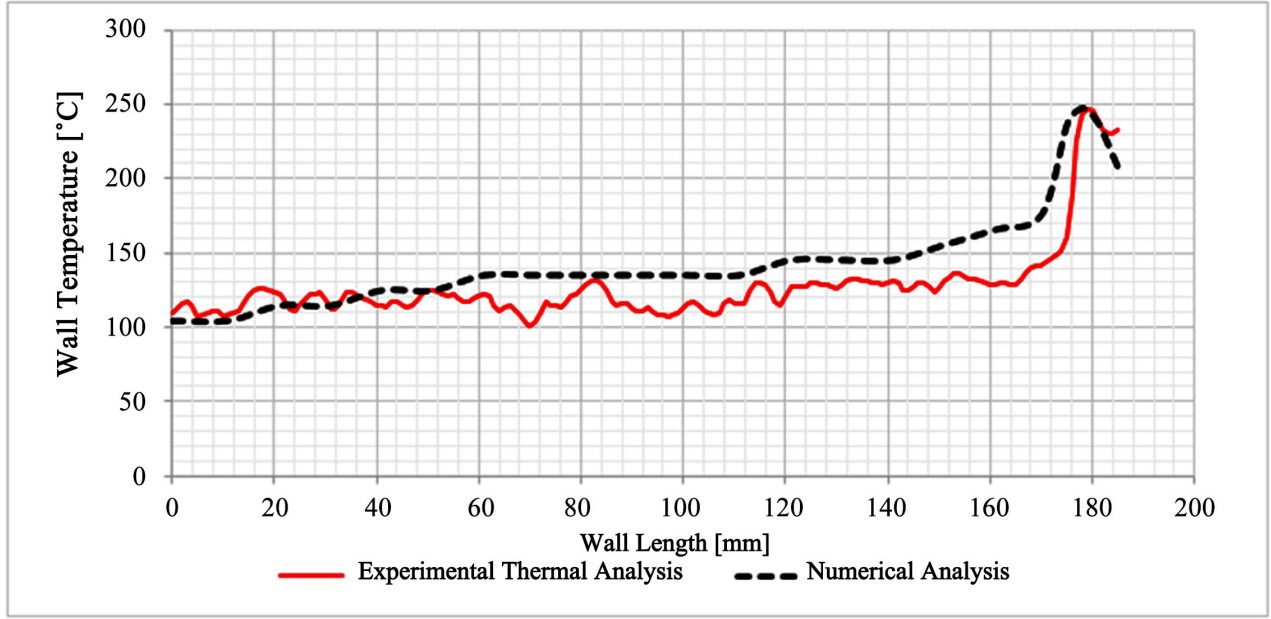

Figure 12. Comparison of temperatures found. 


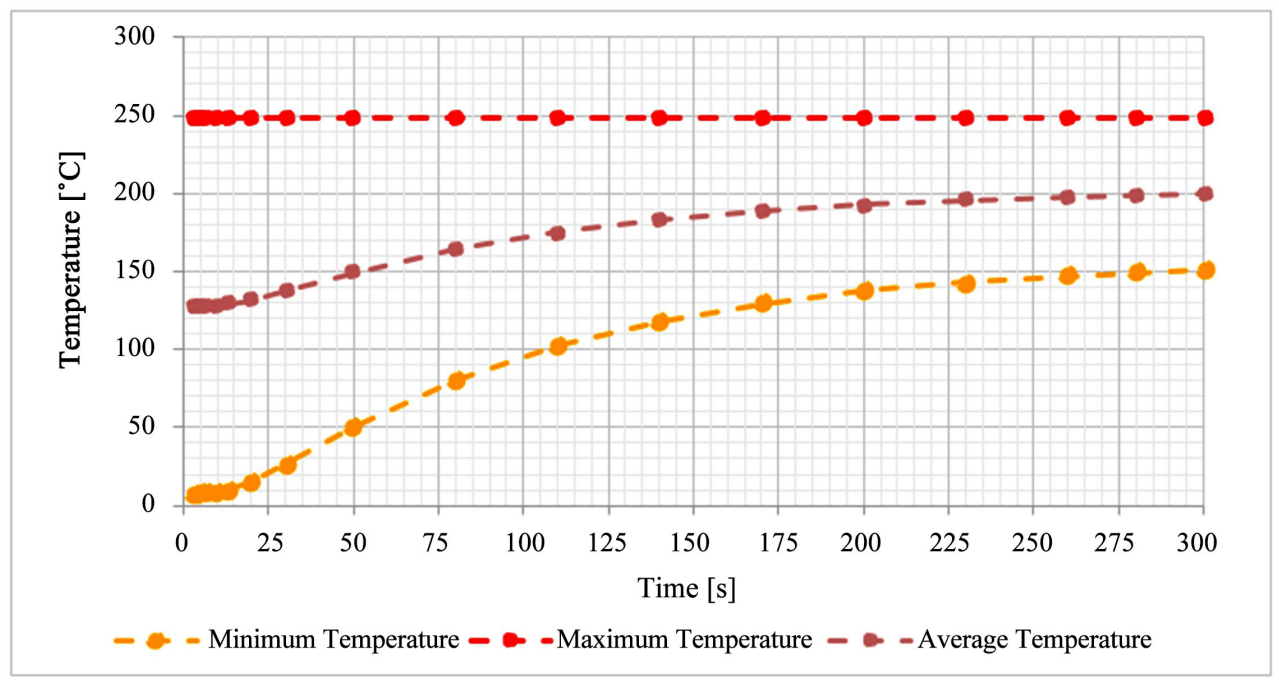

Figure 13. Comparison of results found.

\section{Conclusions}

The simulation is extremely important for process validation, since the functionality of the mechanism studied in the Smc1 border collapsing machine is directly related to heat transfer at its point of application. By applying the numerical simulation the process is understood and validated, being a tool of great utility in the area of engineering to assist in making decisions to perfect the processes, generating an increasingly competitive product in the market.

Finally, the computational method applied numerically was validated experimentally by thermal image analysis captured from the mechanism, presenting points with similar temperature, thus presenting the possibility of applying the study in different processes, as possible improvements in the current mechanism. That is why studies in the field of mechanical engineering are of fundamental importance and maintaining full control of the processes becomes through simulations becomes increasingly attractive to improve the practical processes.

\section{Conflicts of Interest}

The authors declare no conflicts of interest regarding the publication of this paper.

\section{References}

[1] Oba, R. (2015) Simulation and Thermal Analysis of Tunnel Kiln Applied to the Ceramic Industry. Doctoral Thesis, Federal University of Santa Catarina, Florianópolis. (In Portuguese)

[2] Oliveira, M.J. (2014) Thermal Modeling of the Linear Reciprocating Compressor Operating without Lubricating Oil. Master's Dissertation, Federal University of Santa Catarina, Florianópolis. (In Portuguese)

[3] Barban, L.M. (2014) Numerical-Computational Analysis of the Thermal Stresses Induced by Welding. Master's Dissertation, Polytechnic School of the University of São Paulo, São Paulo. (In Portuguese) 
[4] Teixeira, R.R. (2006) Finite Element Modeling for Strain and Creep Analysis in Roller Compacted Concrete. Master's Dissertation, Federal University of Paraná, Curitiba. (In Portuguese)

[5] Eger, R.S. (2010) Modeling of Turbulent Flows under Alternating Rotation. Master's Dissertation, Federal University of Santa Catarina, Florianópolis. (In Portuguese)

[6] Barrios, A.N.S. (2013) Thermal Modeling for Temperature Evaluation in the Milling of Steels for Molds and Dies. Master's Dissertation, University of the State of São Paulo, São Paulo. (In Portuguese)

[7] Pereira, F.D.A.S., Freitas M.S., Silva, J.V.L. and Rosário, J.M. (2014) Study and Improvement of a Modeling Head by Molten Filament Deposition by Means of Thermal Analysis of Finite Elements. VIII National Congress of Mechanical Engineering, Uberlândia, 10 August 2014, 1-8.

http://www.swge.inf.br/PDF/CONEM2014-0305_12192.PDF

[8] Smartmaq Industry and Trade of Machines.

https://smartmaq.com.br/maquinas-cat/coladeira-de-borda/ 